\title{
Interspecies Variation in Pupation Site Preference on Exposure to Different Anti Epileptic Drugs - A Study in Few Species of Drosophila
}

\author{
B. P. Harini \\ Drosophila Culture Laboratory, Department of Zoology, Bangalore University, Bangalore- 560 056, Karnataka, India
}

\begin{abstract}
The present work determine the acute adverse effects produced by commonly used conventional AEDs with respect to their larval pupation site preference in Drosophila species at different doses. Dose dependent action of different AEDs produced a maximal effect on behaviors of Drosophila species on exposure to phenytoin followed by valproiuc acid and carbamezepine which provides an efficient system to study genetic, neurological, and behavioral mechanisms. Such studies are useful for understanding the multiple effects on behavior. Larval pupation site preference is an important event in pre-adult development. Pupation site preferences of Drosophila larvae depend on species-specific cues. The present study revealed that the pupation site preference between species significantly varied on exposure to different AEDs and prefer media at large for pupation at high doses. D. melanogaster, D. ananassae and D. nasuta nasuta do not belong to same species group, but show similarity in their pupation site preference.
\end{abstract}

Keywords: Drosophila species, Pupation site preference, Phenytoin, Valproic acid, Carbamezepine.

\section{Introduction}

Animal studies have demonstrated that AEDs can produce cognitive deficits at dosages less than those required for anatomical teratogenesis (Fisher and Vorhees, 1992). Anatomical and behavioral teratogenesis likely differ in mechanisms since first trimester AED exposure poses the highest risk for anatomical malformations, while third trimester exposure appears to be associated with the highest risk for adverse behavioral effects (Gaily and Meador, 2007). Studies in rats have shown significant AED effects in the developing brain including apoptotic neurodegeneration (Bittigau et al., 2003); neurodevelopmental delay, behavioral disorders or learning disabilities as an outcome of in utero exposure to AEDs and specially VPA (Nicolai et al., 2008). The cognitive side effects of CBZ, PHT and VPA are comparable and associated with modest psychomotor slowing accompanied by decreased attention and memory (Meador, 2005).

PHT is implicated in dose related decline in concentration, memory and mental speed, as well as generating anxiety, aggression, fatigue, and depression (Gillham et al., 1990). Sedation and outbursts of psychotic episodes have been described with PHT at high doses (Levinson and Devinsky, 1999). PHT produces multiple behavioral dysfunctions in rat offspring at sub teratogenic and non growth retarding doses (Adams et al., 1990).

The chronic use of VPA can impair concentration, and also reversible Parkinsonism and cognitive impairment (Nicolai et al., 2008). There is a better recognition of the behavioral phenotype in Fetal valproate syndrome (Dean et al., 2002). Poor concentration and hyperactivity have also been commonly reported on VPA exposure (Kini, 2006).

The active metabolite carbamazepine epoxide is partly responsible for the mild cognitive and psychomotor effects attributed to CBZ (Gillham et al., 1988). The exposure of pregnant rats to $\mathrm{CBZ}$ significantly delayed skull bone development and soft tissues flattening, these structural alterations brought confrontational changes associated to the behavior parameters of the offspring (Rayburn et al., 2004).

At the forefront of behavioral genetics research, $D$. melanogaster has provided important insights into the molecular, cellular and evolutionary basis of behavior (Sokolowski, 2001). Simple behavioral assays are widely applicable for studying the role of genetic and environmental factors on fly behavior on exposure to few AEDs (Sharma $e t$ al., 2010). In many cases the explicit circuits controlling visual (Ting and Lee, 2007), olfactory (Hallem and Carlson, 2004), mechanosensory (Kernan, 2007) and chemosensory (Stocker, 1994) inputs from the peripheral organs (eye, antennae, bristle organs and maxillary palps) have been mapped both physically and functionally. To date, behavioral endpoints in Drosophila have been used primarily to isolate genes that specifically support a given trait rather than as a tool for screening vast numbers of chemicals (Moore et al., 1998).

The larval pupation site preference (PSP) is an important event in Drosophila pre-adult development, because the place selected by the larva can have decisive influence on their subsequent survival as pupae (Sameoto and Miller, 1968). Drosophila sensory systems contribute to detect, localize and provide information about the availability of food and chemical features of environments (Beltrami et al., 2012). The larval PSP has been analyzed by measuring the percentage of larva pupated at different sites viz., cotton, glass and medium and revealed that most of the Drosophila species prefer media and a few species prefer glass and cotton for pupation (Vandal et al., 2003).

Drug induced changes in neural activities that cause complex behavioral changes are often drug induced illness (Nestler, 2005). Memory and learning in rats was affected by phenytoin including decreased radial maze (Tsutsumi et al., 1998). Phenytoin also caused increased adrenaline and noradrenaline concentrations in response to stress in rats (Makatsori et al., 2005) and increased hyper excitability in 


\section{International Journal of Science and Research (IJSR) \\ ISSN (Online): 2319-7064 \\ Index Copernicus Value (2013): 6.14 | Impact Factor (2014): 5.611}

monkeys (Phillips and Lockard, 1996).

The pupation height has been studied by measuring the distance a larva pupated above the surface of the food medium (Schnebel and Grossfield, 1992). Pandey and Singh (1993) and Joshi (1997) have noticed the effect of abiotic and biotic factors on pupation height in various species of Drosophila and concluded that developmental as well as gene environment interactions affects pupation site choice. Thus, total fitness is heavily influenced at the larval stage, and pupation site preference (Markow, 1979). Singh and Pandey (1993) have also reported that pupation height in $D$. ananassae is under polygenic control with a substantial amount of additive genetic variation.

Sokolowski and Hansell (1983) found positive correlation between pupation height and larval foraging behavior in $D$. melanagaster. Studies have shown that larvae are able to assess risks and modify their behavior to suit the environment in a way that increases the odds of survival and pupation position has an impact on survival (Riedl et al., 2007). Singh and Pandey (1991) found intra and inter species variations in pupation height in three species $D$. ananassae, D. bipectinata and D. malerkotliana. Variations among different strains of the same species in pupation height can be attributed to genetic heterogeneity among strains.

The existence of genetically regulated behaviors is of great value for the adaptation of organisms. One aspect of the life cycle of Drosophila, the larval choice of suitable pupation sites has been the subject of different studies and in view of this behavior has on the subsequent pupal viability (Casares et al., 1997). Difference in the choice of pupation sites by Drosophila in the laboratory have been proven to be under genetic control (Markow, 1979).

In light of the above studies the present work determine the acute adverse effects produced by commonly used conventional AEDs with respect to their larval pupation site preference in Drosophila species at different doses. The present study has been assessed for the dose response relationship between AEDs and their behavior in different species of Drosophila.

\section{Materials And Methods}

The fly stocks, D. melanogaster, D. ananassae and $D$. nasuta nasuta were cultured on standard wheat cream agar medium in uncrowded culture condition at $22 \pm 1^{\circ} \mathrm{C}$ (rearing temperature) with a relative humidity of $70 \%$. The progeny from these stabilized stocks treated with PHT $(5,10$ and 15 $\mathrm{mg} / \mathrm{ml}), \operatorname{VPA}(0.2,0.3$ and $0.4 \mathrm{mg} / \mathrm{ml})$ and CBZ $(2,4$ and 8 $\mathrm{mg} / \mathrm{ml}$ ) were used to assess the larval pupation site preference and compared to respective controls.

\section{Larval pupation site preference}

The AEDs were added to wheat cream agar media containing the above said doses and in the said Drosophila species were exposed. Virgin females and unmated males, separately collected were maintained for 5 days in order to age and then transferred to media containing drugs. $5 \mathrm{ml}$ of media was placed in $25 \times 100 \mathrm{~mm}$ sample tubes and a pair of flies was transferred to each vial. Flies were allowed to lay eggs on media supplemented with drugs and the number of eggs laid was recorded. Controls of different species were used for comparison. The vials were screened for the eggs to hatch, complete larval and pupal development. The PSP of the late third instar larvae which enter the wandering stage leaving the media was observed and recorded (Riedl et al., 2007). The numbers of larvae pupated at different sites (cotton, glass wall and media) were counted and tabulated.

\section{Results}

The mean larval PSP in different species of Drosophila on exposure to different AEDs (Fig 1a). D. melanogaster, D. ananassae and $D$. nasuta nasuta control flies prefer to pupate on glass wall. The pupation on glass wall was highest at $5 \mathrm{mg} / \mathrm{ml}(47.7 \pm 0.94)$ in D. melanogaster and least at 15 $\mathrm{mg} / \mathrm{ml}(26.3 \pm 3.32)$. The treated larvae of $D$. ananassae increased pupation on media $(11.5 \pm 1.58$ and $18.6 \pm 5.58)$ and decreased on glass wall $(29.0 \pm 2.01$ and $23.6 \pm 1.89)$ at 10 and $15 \mathrm{mg} / \mathrm{ml}$ when compared to control media and glass pupation. D. nasuta nasuta showed reduction at all the doses on glass wall; $28.1 \pm 3.72$ at $5 \mathrm{mg} / \mathrm{ml}$ and 0.0 at 10 and 15 $\mathrm{mg} / \mathrm{ml}$. The pupation on media was increased in $D$. nasuta nasuta at 10 and $15 \mathrm{mg} / \mathrm{ml}(49.06 \pm 5.03$ and $52.4 \pm 2.31)$ when compared to $D$. melanogaster and $D$. ananassae.

Mean larval PSP on exposure to VPA for Drosophila species is depicted in Fig 1b. D. melanogaster and D. ananassae pupated on glass wall at $0.2 \mathrm{mg} / \mathrm{ml}(46.6 \pm 1.71$, $44.7 \pm 1.41$ ) but decreased to $16.26 \pm 4.13$ and $20.3 \pm 4.5$ at high doses respectively. The pupation on media was highest $(17.1 \pm 1.69)$ and $(12.3 \pm 4.6)$ at $0.4 \mathrm{mg} / \mathrm{ml}$ in D. melanogaster and $D$. ananassae respectively. This indicates that the pupation on media was highest with increased doses. The pupation on glass wall was not found at $0.4 \mathrm{mg} / \mathrm{ml}$ of the larvae treated, whereas the media pupation was increased at $0.3(38.2 \pm 3.46)$ and $0.4 \mathrm{mg} / \mathrm{ml}(42.5 \pm 3.86)$ in D. nasuta nasuta. The glass pupation was least in D. nasuta nasuta compared to D. melanogaster and D. ananassae.

On exposure to CBZ the mean PSP of Drosophila species had shown differences among control and treated (Fig 2c). The mean PSP on glass wall did not differ between treated, while slight increase on media $(5.7 \pm 2.98)$ at $8 \mathrm{mg} / \mathrm{ml}$ in $D$. melanogaster. The highest pupation on media was observed in $D$. ananassae and $D$. nasuta nasuta at all the doses $(5.3 \pm 1.5,8.3 \pm 0.4,11.5 \pm 2.13)$ and $(18.6 \pm 1.89,35.2 \pm 1.75$, 40.4 \pm 2.91$)$. D.nasuta nasuta shows reduced pupation on glass wall at all the doses $(16.3 \pm 3.32,12.1 \pm 2.28,6.7 \pm 1.7)$ respectively. $D$. nasuta nasuta has shown increased pupation on media when compared to D. melanogaster and $D$. ananassae.

\section{Discussion}

The Drosophila flies were exposed to varying doses of antiepileptic drug for three days to determine its effect on behaviors. In preclinical studies on animals, AEDs produce acute adverse effects such as sedation, ataxia, tremor, impairment of motor coordination, disturbance in locomotor activity and alterations in skeletal muscular strength. Grip

\section{Volume 5 Issue 2, February 2016}




\section{International Journal of Science and Research (IJSR) \\ ISSN (Online): 2319-7064}

Index Copernicus Value (2013): 6.14 | Impact Factor (2014): 5.611

strength test is able to evaluate the acute adverse effect potential of AEDs at high (neurotoxic) doses with respect to the reduction of muscular strength (Zadroniak et al., 2009).

Larval pupation site preference is an important event in preadult development. Pupation site preferences of Drosophila larvae depend on species-specific chemical cues (Beltrami et al., 2012). The present study revealed (Fig 1a-c) that the pupation site preference between species significantly varied on exposure to different AEDs and prefer media at large for pupation at high doses. D. melanogaster, D. ananassae and D. nasuta nasuta do not belong to same species group, but show similarity in their pupation site preference i.e., glass wall.

D. melanogaster showed reduced glass wall pupation at high dose $(26.3 \pm 3.32)$ of PHT exposure while D. ananassae (29.0 \pm 2.0 and 23.6 \pm 1.89 ) and D. nasuta nasuta (0.0 and 0.0$)$ at mid and high doses respectively. In case of $D$. nasuta nasuta glass pupation was observed only in control and low dose while pupation on media was highest at mid and high doses. Similar observations were found in other AEDs too.

The animals exposed to PHT showed significant increase in locomotor activity measures. These results confirm a small but growing body of literature that demonstrates that PHT is a behavioral teratogen (Pizzi and Jersey, 1992). The observed mean values of locomotor activity were dose dependent and significantly different among different AEDs exposure on Drosophila species.

Interestingly, the behavioral traits observed were generally dose dependent. The nervous system, the most crucial system in the elicitation of behavior, is formed during development by networks of interacting genes and the physiological structures necessary to generate these behavior patterns. Despite the sources of complexity, the amount of research accomplished has pushed the fruit fly to the forefront of behavioral genetics research (Sokolowski, 2001).

Dose dependent action of different AEDs produced a maximal effect on behaviors of Drosophila species and provides an efficient system to study genetic, neurological, and behavioral mechanisms mediating these effects. AED has an important role in regulating behavior through metabolism; such studies should be useful for understanding the multiple effects on behavior.

\section{Acknowledgement}

B.P.H is grateful to Department of Zoology Bangalore University Jnanbharathi Campus, Bangalore for support and encouragement.

\section{References}

[1] Adams, J, Vorhees, CV \& Middaugh, LD. 1990 Developmental neurotoxicity of anticonvulsants: human and animal evidence on phenytoin. Neurotoxicol Teratol 12, 203-214.

[2] Beltrami, M, Medina-Munoz, MC, Del Pino, F, Ferveur, JF \& Godoy-Herrera, R. 2012 Chemical cues influence pupation behavior of Drosophila simulans and Drosophila buzzatii in nature and in the laboratory. PLoS One 7, e39393.

[3] Bittigau, P, Sifringer, M \& Ikonomidou, C. 2003 Antiepileptic drugs and apoptosis in the developing brain. Ann N Y Acad Sci 993, 103-114.

[4] Casares, P, Carracedo, MC \& García-Florez, L. 1997 Analysis of larval behaviours underlying the pupation height phenotype in Drosophila simulans and $D$. melanogaster. Genet Sel Evol 29, 589-600.

[5] Dean, JC, Hailey, H, Moore, SJ, Lloyd, DJ, Turnpenny, PD \& Little, J. 2002 Long term health and neurodevelopment in children exposed to antiepileptic drugs before birth. J Med Genet 39, 251-259.

[6] Fisher, JE \& Vorhees, CV. 1992 Developmental toxicity of antiepileptic drugs: relationship to postnatal dysfunction. Pharmacol Res 26, 207-221.

[7] Gaily, E \& Meador, KJ. 2007 Neurodevelopmental effects. In: Epilepsy: A comprehensive textbook. (Eds. Engel, J \& Pedley, TA), 2nd Edition. Lippincott Wiliams \& Wilkins, Philadelphia. vol II, Section V. pp. 1225-1233.

[8] Gillham RA, Williams N, Wiedmann KD, Butler E, Larkin JG, Brodie MJ. 1988. Concentration-effect relationships with carbamazepine and its epoxide on psychomotor and cognitive function in epileptic patients. J Neurol Neurosurg Psychiatry 51:929-933.

[9] Gillham, RA, Williams, N, Wiedmann, KD, Butler, E, Larkin, JG \& Brodie, MJ. 1990 Cognitive function in adult epileptic patients established on anticonvulsant monotherapy. Epilepsy Res 7, 219-225.

[10] Levinson, DF \& Devinsky, O. 1999 Psychiatric adverse events during vigabatrin therapy. Neurology 53, 15031511.

[11] Joshi, A. 1997 Laboratory studies of density-dependent selection: Adaptations to crowding in Drosophila melanogaster. Curr Sci 72, 555-562.

[12]Kini, U. 2006 Fetal valproate syndrome: a review. Paediatr Perinat Drug Ther 7, 123- 130.

[13] Makatsori, A, Michal, D, Eduard, U, Bakos, J \& Jezova, D. 2005 Neuroendocrine changes in adult female rats prenatally exposed to phenytoin. Neurotoxicol Teratol 27, 509-514.

[14] Markow, TA. 1979 A survey of intra and interspecific variation for pupation height in Drosophila. Behav Genet 9, 209-217.

[15] Meador, KJ. 2005 Cognitive effects of epilepsy and anti epileptic medications. In: The treatment of epilepsy. Principles and practices. (Eds. Wyllie, E), 4th Edition. Lippincott Williams \& Wilkins, Philadelphia. pp. 11851195.

[16] Moore, MS, DeZazzo, J, Luk, AY, Tully, T, Singh, CM \& Heberlein, U. 1998 Ethanol intoxication in Drosophila: Genetic and pharmacological evidence for regulation by the cAMP signaling pathway. Cell 93, 997-1007.

[17] Nestler, EJ. 2005 Is there a common molecular pathway for addiction? Nat Neurosci 8, 1445-1449.

[18] Nichols, CD, Becnel, J \& Pandey, UB. 2012 Methods to assay Drosophila behavior. J Vis Exp (61) e3795 doi : $10.3791 / 3795$.

[19]Nichols, CD. 2006 Drosophila melanogaster neurobiology, neuropharmacology, and how the fly can

\section{Volume 5 Issue 2, February 2016}




\section{International Journal of Science and Research (IJSR) \\ ISSN (Online): 2319-7064}

Index Copernicus Value (2013): 6.14 | Impact Factor (2014): 5.611

inform central nervous system drug discovery. Pharmacol Ther 112, 677-700.

[20]Pandey, MB \& Singh, BN. 1993 Effect of biotic and abiotic factors on pupation height in four species of Drosophila. Indian J Exp Biol 31, 912-917.

[21] Phillips, NK \& Lockard, JS. 1996 Infant monkey hyperexcitability after prenatal exposure to antiepileptic compounds. Epilepsia 37, 991-999.

[22]Pizzi, WJ \& Jersey, RM. 1992 Effects of prenatal diphenylhydantoin treatment on reproductive outcome, development, and behavior in rats. Neurotoxicol Teratol 14, 111-117.

[23] Rayburn, WF, Gonzalez, CL, Parker, KM \& Christensen, HD. 2004 Chronic prenatal exposure to carbamazepine and behavior effects on mice offspring. Am J Obstet Gynecol 190, 517-521.

[24] Riedl, CA, Riedl, M, Mackay, TF \& Sokolowski, MB. 2007 Genetic and behavioral analysis of natural variation in Drosophila melanogaster pupation position. Fly (Austin) 1, 23-32.

[25] Sameoto, DD \& Miller, RS. 1968 Selection of pupation site by Drosophila melanogaster and D. simulans. Ecology 49, 177-180.

[26] Schnebel, EM \& Grossfield, J. 1992 Temperature effects on pupation-height response in four Drosophila species group triads. J Insect Physiol 38, 727- 732.

[27] Sharma, CS, Nema, RK \& Sharma, VK. 2010 Synthesis, anticonvulsant activity and in silico study of some novel amino acids incorporated bicyclo compounds. S J Pharm Sci 2, 42-47.
[28] Singh, BN \& Pandey, M. 1991 Intra and interspecies variations in pupation height in Drosophila. Indian $J$ Exp Biol 29, 926-929.

[29] Sokolowski, MB \& Hansell, RI. 1983 Elucidating the behavioral phenotype of Drosophila melanogaster larvae: correlations between larval foraging strategies and pupation height. Behav Genet 13, 267-280.

[30] Sokolowski, MB. 2001 Drosophila: genetics meets behaviour. Nat Rev Genet 2, 879- 890.

[31] Stocker, RF. 1994 The organization of the chemosensory system in Drosophila melanogaster: a review. Cell Tissue Res 275, 3-26.

[32] Ting, CY \& Lee, CH. 2007 Visual circuit development in Drosophila. Curr Opin Neurobiol 17, 65-72.

[33] Hallem, EA \& Carlson, JR. 2004 The odor coding system of Drosophila. Trends Genet 20, 453-459.

[34]Kernan, MJ. 2007 Mechanotransduction and auditory transduction in Drosophila.Pflugers Arch 454, 703-720.

[35] Tsutsumi, S, Akaike, M, Ohno, H \& Kato, N. 1998 Learning/memory impairments in rat offspring prenatally exposed to phenytoin. Neurotoxicol Teratol 20, 123- 132.

[36] Vandal, NB, Modagi, SA \& Shivanna, N. 2003 Larval pupation site preference in a few species of Drosophila. Indian J Exp Biol 41, 918-920.

[37]Zadrozniak, A, Wojda, E, Wlaz, A \& Luszczki, JJ. 2009 Characterization of acute adverse-effect profiles of selected antiepileptic drugs in the grip-strength test in mice. Pharmacol Rep 61, 737-742.

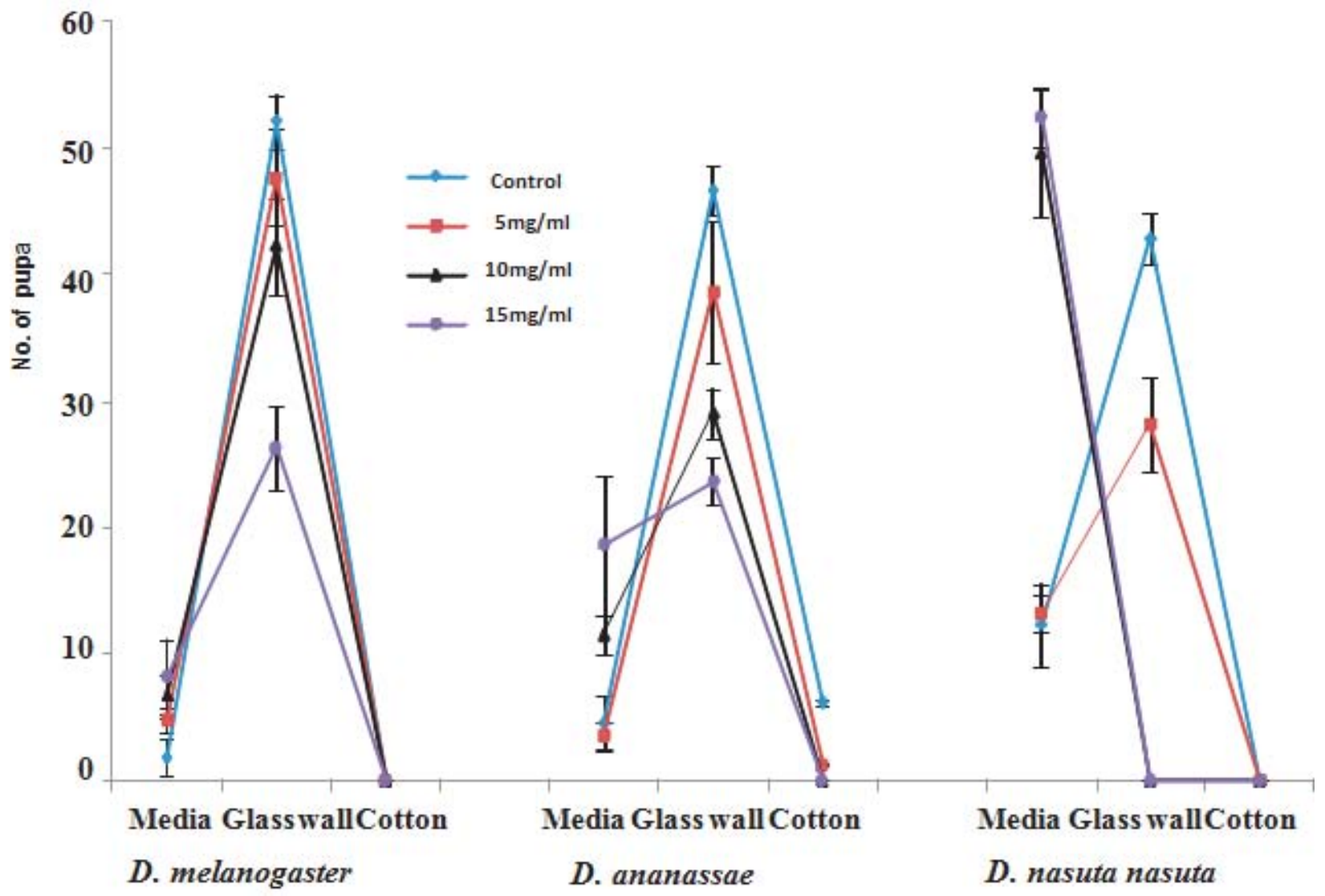

Pupation sites of Drosophila species

Figure 1a: Mean pupation site preference of Drosophila species on exposure to Phenytoin 


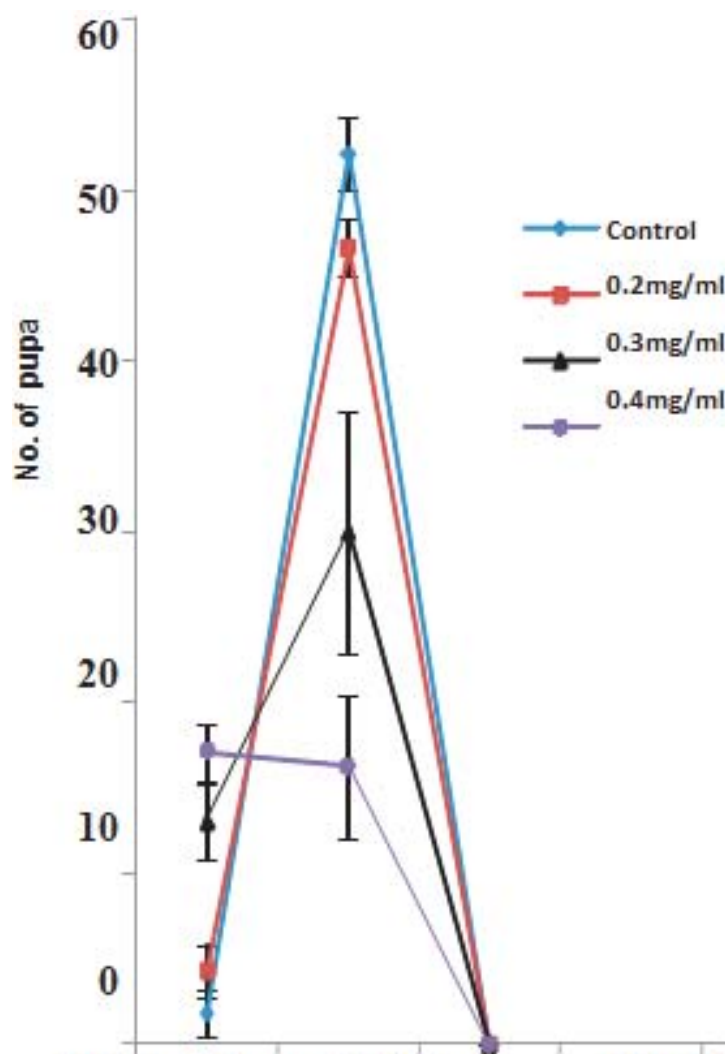

Media Glass wall Cotton

Media Glass wall Cotton

Media Glass wall Cotton

D. melanogaster

D. ananassae

D. nasuta nasuta

Pupation sites of Drosophila species

Figure 1b: Mean pupation site preference of Drosophila species on exposure to Valproic acid

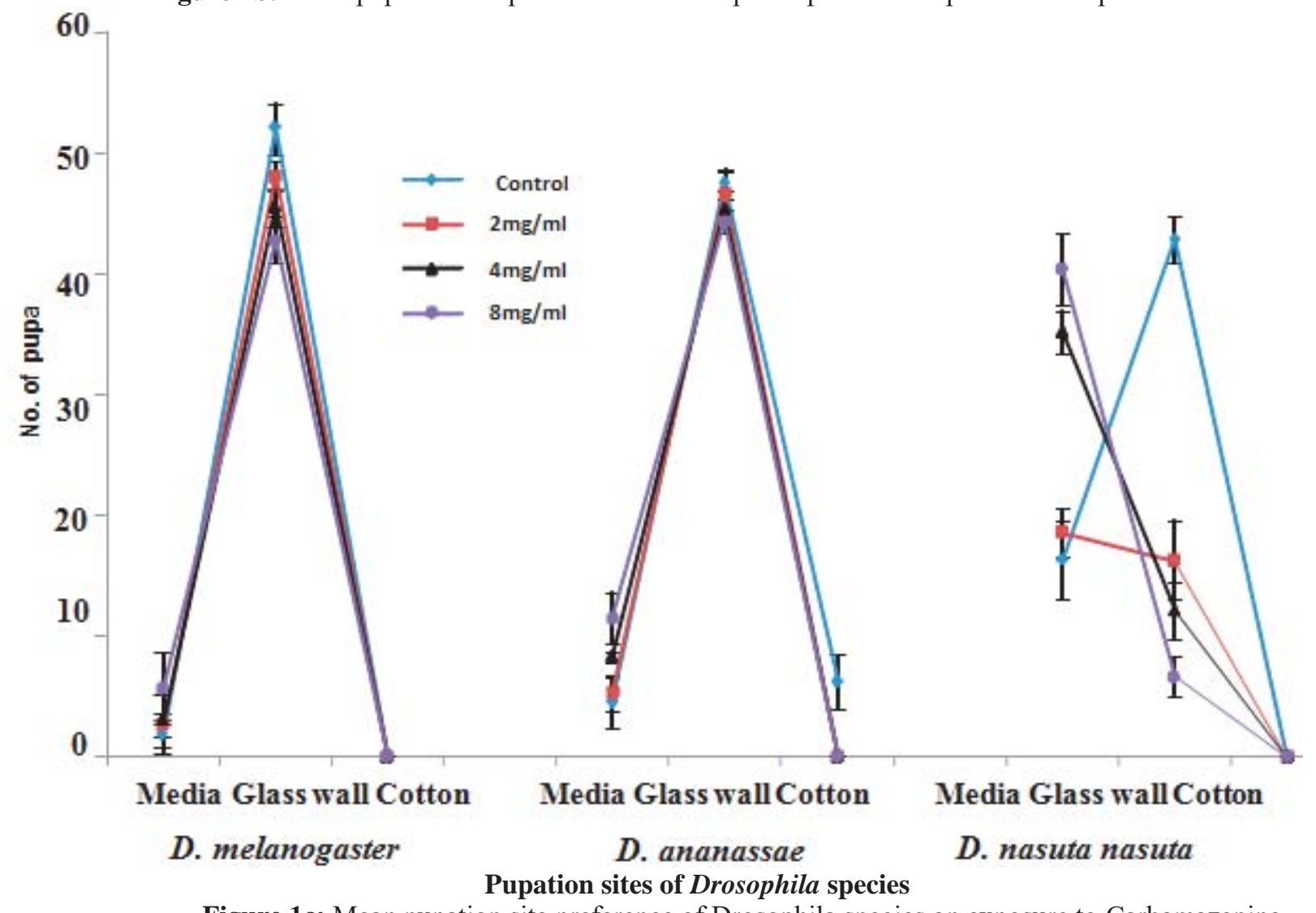

Figure 1c: Mean pupation site preference of Drosophila species on exposure to Carbamazepine 